\title{
Certified Nursing Assistants' Perceptions And Generational Differences
}

\author{
Debra Hagerty, Armstrong State University, USA
}

Janet R. Buelow, Armstrong State University, USA

\begin{abstract}
Certified nursing assistants (CNAs) are the heart and soul of long-care facilities. This study surveyed their perceptions of nursing home administrators, supervisors, and coworkers, and then compared generational differences. Regardless of generation, CNAs reported a high sense of intrinsic satisfaction, commitment to their nursing home, and supervisor support. However, all generations of CNAs perceived their administrators as rather insensitive by not showing concern for their health, not calling in additional help when needed, nor making allowances for family emergencies. Two significant generational differences were found: 1) older CNAs, or baby boomers, felt their supervisor didn't understand their work problems and needs and 2) younger CNAs (Millennials) reported more internal gossiping and negative peer interactions than did older CNAs. These findings are useful as administrators and supervisors strive to create a supportive work environment.
\end{abstract}

Keywords: Certified Nursing Assistant; Generational Differences; Supervisor Support; Work Environment

\section{INTRODUCTION}

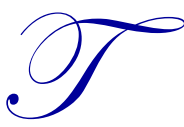

he support and nurturing of certified nursing assistants (CNAs) is a continuous challenge for nursing home administrators as they endeavor to maintain a stable workforce in their facilities. Turnover rates in nursing homes are recognized as one of the highest in the healthcare field, with a national median rate over 50\% and many nursing homes having turnover rates of 100\%. Multiple studies have demonstrated high turnover impacts both staff morale and resident quality of care (American Health Care Association, 2012; Castle, Engberg, and Men, 2007). Banaszak-Holl and her colleagues (2015) found that turnover rates are impacted by nursing homes' organizational cultures. Other studies have found specific administrative practices and leadership styles impact CNA intrinsic satisfaction and intent to leave their jobs (Donoghue \& Castle, 2009; Decker, HarrisKojetin, \& Bercovitz, 2009). These primary studies provide evidence that nursing home administrative and leadership styles and staff turnover have a definite relationship. The original purpose of this study was to identify CNA perceptions of their leaders' styles and support, their work culture, intrinsic satisfaction and commitment.

However, a composite, average voice of CNAs is impractical, since CNAs are not composed of homogenous generations. The generational diversity among CNAs adds to the challenge of providing the most supportive and engaging work environment. This study examines CNAs' perceptions of support from their administrators, supervisors, and coworkers and then compares these perceptions by generation. The findings may help administrators and other nursing home leaders provide more targeted approaches to keep all generations of CNAs intrinsically satisfied and feeling valued within their facilities.

\section{Perceptions of Leaders and Generational Differences}

Within healthcare and long-term care organizations, leadership behaviors are found to impact quality of care, staff satisfaction, and intention to leave (Donoghue \& Castle, 2009; Decker et al, 2009; Shacklock \& Brunetto, 2011). Hospital studies of nurses and CNAs reveal that both supervisor-staff relationships and co-worker relationships contribute to their organizational commitment, retention, and work-related stress (Shacklock \& Brunetto, 2011; Farr-Wharton, Brunetto, \& Shacklock, 2011; Brunetto, Farr-Wharton, Shacklock 2010). In long-term care facilities, supportive supervision is shown to be a significant factor for both CNA job satisfaction and intent to (not) leave their jobs (Choi \& Johantgen, 2012; Castle \& Decker, 2011). In summary, CNAs' perceptions of nursing home 
administrators and supervisors are associated with their job satisfaction and intent to leave their job, but it is unknown how to ensure specific supportive perceptions among all working CNAs.

Several studies show significant differences in the perspectives of different generations (Shacklock \& Brunetto, 2011; Calhoun \& Strasser, 2005; Tourangeare, Wong, Saari, \& Patterson, 2014). These studies find that there seem to be generational differences in how individuals perceive others, treat others, and believe others should be treated. In other words, those who share similar birth years, seminal historical events, and economic events may perceive things similarly, as a generational cohort, than those born and raised in different times. Typically, generations are divided into baby boomers, Generation X, and Millennials (also referred to as Generation Y.) Baby boomers, born between 1946 and 1964, are regularly recognized for their willingness to work and are often referred to as workaholics (Saber, 2013). Generation X, born between 1965 and 1980, are frequently referred to as "latch-key kids," as their parents were the workaholics. Gen Xers are thought to refrain from giving respect based on cultural symbols such as titles, age or seniority; respect must be earned by demonstrated expertise (Codier et al, 2011). Millennials, born between 1980 and 2000, grew up in a world with massive information at their fingertips. They are known as being very demanding and want quick responses (Weingarten, 2009; Jobe, 2014).

Undoubtedly, the potential for stress and conflict among generations of CNAs is high based solely on the demanding work and an environment that is filled with uncertainty, ambiguity and complexity. When staff and supervisors do not understand each other's generational culture, styles, and backgrounds, conflict may arise. Older baby boomers may consider Gen X workers as slackers and consider Millennials as demanding and disloyal. Likewise, Gen X workers may not respect the experience and stability baby boomers bring to their daily tasks. Understanding generational characteristics and perceptions of their work environment is very important, as this may impact staff relationships and work satisfaction. Likewise, generational differences may require supervisors to utilize generationally tailored strategies to promote success. Successful organizations nourish retention among generations, recognizing that keeping staff is as important as finding and recruiting them (Calhoun \& Strasser, 2005; Ferri-Read, 2016).

\section{METHODOLOGY}

This is a cross sectional study of four nursing homes and uses an exploratory, descriptive approach to analyze the data; approval was received from our university Institutional Review Board.

\section{Recruitment and Sample}

During a regional National Association Directors of Nurse Administration meeting, this proposed study was described, the questionnaire draft shared, and nursing facilities were invited to participate. Nursing home directors from four facilities were interested and agreed to allow their CNAs to complete the survey during change of shift times, with all completed surveys remaining completely anonymous and immediately brought to the authors' university after completion. A total of 120 surveys were distributed and 100 completed surveys were returned.

The sample of CNAs consisted of all three generations: Millennials, age 18 - 34 years (23\%); generation X, age 3550 years (57\%); and Baby Boomers, age 51-69 years (20\%.) Twenty nine percent of the CNAs worked in their facility less than two years, $53 \%$ worked from 2 to 5 years, and $18 \%$ worked between 5 and 10 years in their facility. Nearly half (48\%) the workers staffed the day shift, $36 \%$ worked the evening shift and a small percent $(16 \%)$ covered the night shift. Nearly all CNAs $(92 \%)$ were employed full-time.

\section{Instrument and Measures}

The survey was two back-to-back pages with simple directions. It included a short introduction and sections of 6point Likert scale statements in which CNAs circled their degrees of agreement or disagreement. Each section on the questionnaire had 3 to 6 statements in the areas of: administrators, supervisors, intrinsic satisfaction and commitment, and workplace climate. The questions were modified from surveys used in hospital studies and significantly shortened to be appropriate for CNAs in nursing homes (Shacklock \& Brunetto, 2011; Farr-Wharton et al, 2011). With these shorter scales, we calculated Cronbach alpha scores to ensure reliability of scales. The four 
scales and their Cronbach alphas are perceptions of administrators (0.89); perceptions of supervisors (0.91); the workplace climate (0.89); and job satisfaction and commitment (0.72).

\section{Data Analysis}

The data were entered into SPSS for statistical analysis and a p level of .05 was set for significance. After descriptive analysis for CNA demographics, work history, and perceptions were examined, an analysis of variance (ANOVA) was conducted to assess if there were differences in any of these variables by nursing home. No significant differences were found.

We then assessed if length of job tenure impacted perspectives with a multivariate analysis of covariance (MANCOVA) and found that length of job tenure did not seem to impact CNA perceptions. Lastly, we compared generational differences with an analysis of variance (ANOVA.)

\section{FINDINGS}

\section{Intrinsic Job Satisfaction and Commitment}

The questions for this area asked CNAs overall how they feel most days about their job. Most CNAs felt a real sense of accomplishment (intrinsic satisfaction) with their work, with the Millennials reporting the least positive feelings, but still very high (scores ranged from 4.9 to 5.47 out of a 6 point scale.) The questions regarding commitment towards their nursing home reveal that at best, CNAs are ambivalent, with feelings ranging between slightly disagree to slightly agree (mean scores range from 3.67 to 4.44 on 6 point scale.) All three generations rate their highest level of commitment with feeling they are a "strong part of their nursing home" and all three generations also feel weakest in being "connected to their nursing home" Consistently the Millennials reported the lowest opinions of satisfaction and commitment, while all generations were relatively close and there were no statistically significant differences.

\section{Perceptions of Administrators}

CNAs' perceptions of administrators were considerably lower than their job satisfaction and commitment (2.32 to 3.35 on a 6 point scale). Generally, CNAs felt that their administrators did not care about them, their opinions and advancement, and did not call in additional help when needed. The Millennials reported the most positive opinions of their administrators in four of the six questions and the baby boomers reported the lowest perceptions in five of the six questions. The three strongest negative ratings were that administrators do not call in additional help when needed, do not show concern for their personal health or their families and don't make allowances for family emergencies. Again, there were no statistically significant differences.

\section{Perceptions of Supervisors}

For all generations, the perceptions of supervisors were much more positive than of the administrators, with ratings ranging from 3.22 to 5.64 on a 6 point scale. The most positive mean scores for all generations indicate that CNAs feel: 1) their supervisor is satisfied with their work, and 2) their supervisor knows how good they are at their job. Again, the millennials report the most positive opinions and the baby boomers report the most negative perceptions. One statistically significant difference was found here. Baby boomers felt significantly less than their younger cohorts, the millennials, that their supervisor understood their work problems and needs (3.22 versus 4.65, respectively, $\mathrm{p}=0.011$ ).

\section{Workplace Climate}

The last section of questions asks about witnessing negative coworker interactions. The questions were worded in third person, due to a natural tendency to think the best of ourselves (social desirability bias) (Codier et al, 2011). The three questions asked CNAs if they see or hear other staff perform specific negative actions; ratings ranged from 2.83 to 4.57 on a 6 point scale with the higher the score the more strongly staff saw negative behaviors. For this 
area, on all three questions, Millennials reported the most negative perceptions of workplace climate and had statistically significant poorer perceptions than their older cohorts on hearing staff talk about others behind their back ( 4.57 versus 2.95 , respectively, $\mathrm{p}=0.021$ ).

\section{DISCUSSION AND IMPLICATIONS}

Overall, we found that most CNAs feel a positive intrinsic satisfaction about their work. However, two findings are concerning and have relevant application to current nursing homes. First, is that CNAs, regardless of generation, perceived administrators as rather insensitive, who lack concern for them, their families or need for additional help. While this finding was not statistically significant, it is critically important. Nursing home administrators are required to have significant human resources competencies as noted in their administrative examination (Seigel \& Zysberg, 2016). Also, in light of the high job turnover rates in this industry, the need for better administrator-staff relationships is noted (Bureau of Labor Statistics, U.S. Department of Labor, 2016). Primary research noted above recognizes the relationship between leadership behaviors and intent to turn over in the long-term care industry.

The second significant finding involves generational differences. CNAs did differ significantly by generation in two areas: baby boomers, more than younger CNAs, didn't believe their supervisor understood their work problems and needs and Millennials, more than their older cohorts, believed that staff talked about each other behind their backs and that helpfulness to new staff was being withheld. In other words, older CNAs felt less support from their supervisors and younger CNAs felt less support from their coworkers. These findings are statistically significant, as well as practically relevant.

These findings are significant and responsive plans should involve both administrators and frontline supervisors. Supervisors, who CNAs appear to value, can act as a buffer as workloads increase and additional help is needed. They can share openly how administrators are struggling to find help. Likewise, administrators may want to find personal ways of showing concern for the CNAs' health and families. Developing relationships among staff members may be part of the viable approach. Baby boomers sharing their expertise or mentoring their younger cohorts needs to be included, while at the same time recognizing these older CNAs for their valuable support.

Older CNAs contribute a great deal to the health and well-being of residents, as well as the social climate of a facility. If these CNAs do not feel understood and valued by their supervisors, they will not feel inclined to support younger CNAs. All CNAs expect and deserve a supportive work climate. Negative feelings, disrespectful conversations and unhelpfulness may lead an already stressful environment to one that breeds incivility and impacts the residents' quality of care too. Staff disrespect and negative gossip can create both productivity and morale issues, as well as liability issues if the gossip is deemed "malicious harassment." Several methods of addressing this concern range from addressing specific perpetrators (supervisors or CNAs) privately with positive coaching; providing staff in-services on positive internal climate and teamwork; and creating problem-solving teams that address low morale.

It is essential that administrators watch and address negativity at its infancy. They cannot ignore these workplace challenges, as the slower they are addressed, the more difficult they will be to dissipate. A long-term care environment requires significant collaborative practices to ensure the delivery of quality care. Without cooperation among multiple generations of CNAs, the care for residents will suffer and high staff turnover will ensue.

\section{Limitations}

Several limitations must be recognized in our study. First, our study used facilities whose administrators welcomed us to survey their staff. This reflects a positive selection bias, as these administrators most likely believed that their staff were likely to cooperate and were not afraid to see their perceptions. Second, our study used a convenience sample of CNAs, which again reflects only those participants motivated to provide their opinions. CNAs could easily avoid the researchers, as no pressure was provided to participate in the survey. With these limitations, our findings most likely are more positive than perceptions of CNAs in general. 


\section{CONCLUSION}

This study addresses important gaps in the literature. According to the Bureau of Labor Statistics (BLS), the job forecast for CNAs is projected to grow 18 percent from 2014 to 2024, faster than the average for all other occupations. Furthermore, this workforce will continue to be multigenerational as the US population ages. The need for understanding CNA perceptions and generational differences is crucial in ensuring positive and fruitful working conditions. Administrators and supervisors are encouraged to step up to this challenge with responsive plans that recognize the strengths and needs to support and retain their CNAs.

\section{AUTHOR BIOGRAPHIES}

Dr. Debra Hagerty has been a licensed administrator for post-acute long-term care facilities and a certified director of nursing services in long-term care for over 30 years. Dr. Hagerty has also taught at multiple universities more than 5 years specializing in nursing, leadership and strategies for success. Dr. Hagerty was awarded a State of Michigan leadership award, The Nightingale Award in Long-term and Rehabilitation, for her contribution to the nursing profession and excellence in care to geriatric patients. Dr. Hagerty has published both internationally and nationally emphasizing quality care, collaboration and transformational leadership.

Email: Debra.Hagerty@armstrong.edu

Dr. Janet Buelow, PhD, MSN, MPH, has an educator for over twenty years and presently is a professor of Health Services Administration. She specializes in quality improvement management, patient advocacy and interprofessional collaboration. Email: Janet.Buelow@armstrong.edu (contact author)

\section{REFERENCES}

American Health Care Association (2012). Staffing Report 2012. Retrieved from https://www.ahcancal.org/research_data/staffing/Documents/2012_Staffing_Report.pdf

Banaszak-Holl J, Castle N, Lin M, Shrivastwa N, Spreitzer G (2015). The role of organizational culture in retaining nursing workforce. The Gerontologist, 55(3), 462-471.

Brunetto Y, Farr-Wharton R, Shacklock K.H. (2010). The impact of supervisor-subordinate relationships on morale: implications for public and private sector nurses' commitment. Human Resource Management Journal, 20(2), 206-225

Bureau of Labor Statistics, U.S. Department of Labor. (2016). Nursing Assistants and Orderlies. Occupational Outlook Handbook, 2016-17 Edition. Retrieved from http:/www.bls.gov/ooh/healthcare/nursing-assistants.htm\#tab-6

Calhoun SK, Strasser PB. (2005) Generations at work. AAOHN Journal, 53(11), 469-71.

Castle N, Decker, F. (2011). Top management leadership style and quality of care in nursing homes The Gerontologist, 51(5), 630-642.

Castle N, Engberg J, Men A. (2007). Nursing home staff turnover: impact on nursing home compare quality measures. The Gerontologist, 47(5), 650-666.

Choi J, Johantgen M. (2012). The importance of supervision in retention of CNAs. Research in Nursing \& Health, 35, 187-199.

Codier E, Freel M, Kamikawa C, Morrison P. (2011) Emotional intelligence, caring and generational differences in nurses. International Journal of Human Caring, 15(1), 49-55.

Decker F, Harris-Kojetin L, Bercovitz A. (2009). Intrinsic job satisfaction, overall satisfaction, and intention to leave the job among nursing assistants in nursing homes. The Gerontologist, 49(5), 596-610.

Donoghue C, Castle N. (2009) Leadership styles of nursing home administrators and their association with staff turnover. The Gerontologist, 49(2), 166-174.

Farr-Wharton R, Brunetto Y, Shacklock K. (2011) Professionals' supervisor-subordinate relationships, autonomy and commitment in Australia: a leader-member exchange theory perspective. The International Journal of Human Resource Management, 22(17), 3496-3512.

Ferri-Reed J. (2016). Know your xyzs: understanding and harnessing multigenerational talent. Quality Progress 2016, March, $19-23$

Jobe LL. (2014). Generational differences in work ethic among 3 generations of registered nurses. Journal of Nursing Administration, 44(5), 303-308.

Liang YW, Hsieh Y, Lin YH, Chen YW. (2014).The impact of job stressors on health-related quality of life of nursing assistants in long-term care settings. Geriatric Nursing, 35, 114-119.

Myers K, Sadaghiani K. (2010). Millennials in the workplace: a communication perspective on millennials' organizational relationships and performance. Journal of Business and Psychology, 25(2), 225-238. 
Saber DA. (2013) Generational differences of the frontline nursing workforce in relation to job satisfaction. What does the literature reveal? The Health Care Manager, 32(4), 329-335.

Seigel E, Zysberg L. (2016). Licensed nursing home administrator preparation and role variations. Annals of Long Term Care, 24(3), 28-36.

Shacklock K, Brunetto Y. (2011). The intention to continue nursing: work variables affecting three nurse generations in Australia. Journal of Advanced Nursing, 68(1), 36-46. doi:10.1111/j.1365-2648.2011.05709.x

Tourangeare AE, Wong M, Saari M, Patterson E. (2014) Generational-specific incentives and disincentives for nurse faculty to remain employed. Journal of Advanced Nursing, 75(5), 1019-1031.

Weingarten R. (2009). Four generations, one workplace: a gen x-y staff nurse's view of team building in the emergency department. Journal of Emergency Nursing, 35(1), 27-30. 